In the 2008 election, the majority of older persons failed to vote for the winner, instead opting for the Republican instead of Democrat Barack Obama This trend continued in the 2012, but not in 2016 when older persons favored Republican Donald Trump. Studies of prior elections suggest that although age may have an effect on voting behavior, race was a much stronger predictor of voting choices. This presentation begins by discussing partisan leanings as a possible factor for why older voters prefer Republican candidates. It then presents views regarding health care issues by different age-groups and whether there is evidence for age-bloc voting in support of old-age retirement programs in the 2012 and 2016 elections. Next, it compares the results from the elections, focusing on age-groups and race/ethnicity, and discusses voting behaviors by region. Findings indicate that race/ethnicity and region tend to be stronger predictors of voting choices than age-groups.

\section{ORGANIZING SENIORS TO PROTECT THE HEALTH SAFETY NET: THE WAY FORWARD}

C. Regan ${ }^{1}$, L. Sharma, MA², K.S. Villers, $\mathrm{MUA}^{3}, 1$. Community Catalyst, Boston, Massachusetts, United States, 2. Community Catalyst, Boston, MA, USA, 3. Community Catalyst, Boston, MA, USA

Over the past century, the organized voice of seniors has been critical in building the U.S. health safety net. Since the 2016 election of Donald Trump to the presidency, that safety net, particularly the Medicaid program, is in jeopardy. As we have seen with the rise of the Tea Party, senior support for healthcare programs-even programs that they use in large numbers-cannot and should not be taken for granted. This presentation provides a brief history of senior advocacy and an overview of the current senior organizing landscape. It also identifies opportunities for building the transformational organizing of low-income seniors needed to defend against sustained attacks on critical programs. Several suggestions are made, drawn from years of work in philanthropy, advocacy and campaigns, for strengthening the ability to organize seniors - particularly low-income seniors- into an effective political force advocating for Medicaid and other safety-net programs.

\section{THE POTENTIAL CONSEQUENCES FOR OLDER HISPANICS OF THE TRUMP ADMINISTRATION'S ASSAULT ON HEALTH AND SOCIAL PROGRAMS}

J.L. Angel ${ }^{1}$, N. Berlinger, $\mathrm{PhD}^{2}, 1$. The University of Texas at Austin, Austin, Texas, United States, 2. The Hastings Center, Garrison, NY, USA

Health and social welfare policy proposals put forth by the Trump administration and Republican-controlled Congress could have huge impacts on low-income groups. This presentation focuses on the Mexican-origin population who form the largest Hispanic subgroup. A demographic portrait highlights the unique sources of vulnerability for those of Mexican origin, particularly among the immigrant generation. Given rising health care costs, lower use of nursing homes, and greater propensity to live with grown children, prevailing economic disadvantage has serious consequences for this population. More restrictive immigration policies could make family reunification difficult. Moreover, because of labor-force disadvantages, low-income
Mexican-origin individuals have limited private insurance as they approach retirement. Consequently, Mexican-origin elders rely on Medicaid, excluding late-life migrants who do not qualify for benefits for at least five years. The potential effects of Republican efforts to repeal and replace the Patient Protection and Affordable Care Act for older Hispanics will also be discussed.

\section{SESSION 1350 (SYMPOSIUM)}

POLICY SERIES: MISSING FROM MEDICARE: WHERE ARE WE ON ORAL, HEARING, AND VISUAL HEALTH Chair: B.W. Lindberg, The Gerontological Society of

America, Washington, District of Columbia

This session will highlight the policy changes needed to ensure that Medicare beneficiaries receive care in the critical areas of oral, hearing, and visual health. The panel will discuss current policy proposals and advocacy efforts, and will include experts and key stakeholders in the field.

\section{SESSION 1355 (SYMPOSIUM)}

\section{PRODUCTIVE AGING: WORK AND ITS RELATION TO CAREGIVING AND SELF-EMPLOYMENT}

Chair: S. Park, Washington University in Saint Louis, Saint

Louis, Missouri

Discussant: N. Morrow-Howell, Washington university in

St.Louis, St.Louis, Missouri

As one of the major domains of productive engagement, this symposium focuses on work. The research papers use diverse designs and data sources across the U.S. to explore the intersectionality of work and caregiving, as well as characteristics of self-employment. The first paper focuses on the work-caregiving conflict among employed daughters caring for older parents in a sample of 89 intergenerational family caregivers. The findings show preparedness for caregiving and perceived stress were significant predictors of work strain. The second paper examines the relationship between employment benefits and retirement savings among both male and female care-giver employees (ages 50-57 in 2014) using the 1979 National Longitudinal Survey of Youth (NLSY79) (1994-2014). Findings suggest those with more paid vacation days and access to flexible work hours have higher retirement savings. The third paper examines the effect of a Paid Family Leave program in California (CA-PFL) on employment among older female caregivers with data from multiple years (2000-2014) of the Current Population Survey (CPS). Results show a significant increase in the likelihood of working and decrease in the likelihood of being not employed for those covered by paid family leave. The final paper documents the characteristics of self-employed older adults using the Health and Retirement Study (HRS). Results indicate age, being male, volunteering, risk tolerance, and reporting better health, earnings and wealth were positively associated with selfemployment. These studies identify barriers and facilitators in employment and self-employment, and suggest how public programs, organizational and policy level supports enhance productive engagement in work 